\title{
Identification of novel multi-stage histone deacetylase (HDAC) inhibitors that impair Schistosoma mansoni viability and egg production
}

Alessandra Guidi ${ }^{1}$, Fulvio Saccoccia', Nadia Gennari², Roberto Gimmelli', Emanuela Nizi ${ }^{3}$, Cristiana Lalli', Giacomo Paonessa ${ }^{2}$, Giuliana Papoff ${ }^{1}$, Alberto Bresciani ${ }^{2}$ and Giovina Ruberti ${ }^{i^{*}}$ (D)

\begin{abstract}
Background: Novel anti-schistosomal multi-stage drugs are needed because only a single drug, praziquantel, is available for the treatment of schistosomiasis and is poorly effective on larval and juvenile stages of the parasite. Schistosomes have a complex life-cycle and multiple developmental stages in the intermediate and definitive hosts. Acetylation and deacetylation of histones play pivotal roles in chromatin structure and in the regulation of transcription in eukaryotic cells. Histone deacetylase (HDAC) inhibitors modulate acetylation of several other proteins localized both in the nucleus and in the cytoplasm and therefore impact on many signaling networks and biological processes. Histone post-translational modifications may provide parasites with the ability to readily adapt to changes in gene expression required for their development and adaptation to the host environment. The aim of the present study was to screen a HDAC class I inhibitor library in order to identify and characterize novel multi-stage hit compounds.

Methods: We used a high-throughput assay based on the quantitation of ATP in the Schistosoma mansoni larval stage (schistosomula) and screened a library of 1500 class I HDAC inhibitors. Subsequently, a few hits were selected and further characterized by viability assays and phenotypic analyses on adult parasites by carmine red and confocal microscopy.

Results: Three compounds (Sml-124, Sml-148 and Sml-558) that had an effect on the viability of both the schistosomula larval stage and the adult worm were identified. Treatment with sub-lethal doses of Sml-148 and Sml-558 also decreased egg production. Moreover, treatment of adult parasites with Sml-148, and to a lesser extent Sm-124, was associated with histone hyperacetylation. Finally, Sml-148 and Sml-558 treatments of worm pairs caused a phenotype characterized by defects in the parasite reproductive system, with peculiar features in the ovary. In addition, Sml-558 induced oocyte- and vitelline cell-engulfment and signs of degeneration in the uterus and/or oviduct.

Conclusions: We report the screening of a small HDAC inhibitor library and the identification of three novel compounds which impair viability of the S. mansoni larval stage and adult pairs. These compounds are useful tools for studying deacetylase activity during parasite development and for interfering with egg production. Characterization of their specificity for selected S. mansoni versus human HDAC could provide insights that can be used in optimization and compound design.
\end{abstract}

Keywords: Schistosoma mansoni, HDAC inhibitors, Parasite reproductive systems

\footnotetext{
*Correspondence: giovina.ruberti@cnr.it

${ }^{1}$ National Research Council, Institute of Cell Biology and Neurobiology,

Campus A. Buzzati-Traverso, Monterotondo (Roma), Italy

Full list of author information is available at the end of the article
}

(c) The Author(s). 2018 Open Access This article is distributed under the terms of the Creative Commons Attribution 4.0 International License (http://creativecommons.org/licenses/by/4.0/), which permits unrestricted use, distribution, and reproduction in any medium, provided you give appropriate credit to the original author(s) and the source, provide a link to the Creative Commons license, and indicate if changes were made. The Creative Commons Public Domain Dedication waiver (http://creativecommons.org/publicdomain/zero/1.0/) applies to the data made available in this article, unless otherwise stated. 


\section{Background}

Parasitic diseases cause morbidity and mortality, particularly in the poorest regions of the world. Schistosomiasis is considered the second most important parasitic disease behind malaria in terms of its socio-economic and public health importance, and prevalence in the developing world. It has been estimated that globally over 200 million people are infected with the parasites with a vast majority of them (85\%) living in sub-Saharan Africa [1-3]. Schistosoma mansoni, S. haematobium and S. japonicum are the three most relevant species for human infections [4].

Schistosomes, like other trematodes, display a complex life-cycle which comprises both free-living larvae and parasitic forms with several developmental stages [5]. Throughout its life-cycle, $S$. mansoni must reset its metabolism in order to cope with different living conditions dictated by a variety of environments; drastic changes occur during its development and the transition from cercariae into adult worms. Moreover, whereas most of the trematodes are hermaphrodites, schistosomes are sexually dimorphic and pairing of males and females is required for the maturation of female worms and the production of eggs [6-8]. The eggs produced by sexually mature adult females play a key role in both disease transmission after their release in the environment and pathology as they are causing inflammatory processes and granuloma formation in the host tissues leading to organ failure.

Praziquantel (PZQ) is essentially the only drug used for the treatment of schistosomiasis. It is very effective against adult worms of all three Schistosoma species [9, 10], but unfortunately, it is poorly active on juvenile and schistosomula immature stages both in vivo and in vitro [11-14] and does not prevent re-infection [15, 16]. In addition, widespread use of PZQ in both humans and domestic animals, along with the identification of field [17-20] and laboratory isolates [21-24] with reduced susceptibility to PZQ raise serious concerns about the risk of selection of drug-resistance strains. Therefore, new schistomicidal drugs that target multiple stages of the parasite are needed.

Interestingly, it has been suggested that parasites and cancer cells have several properties in common [25]: the ability to survive in the host by hiding and escaping the immune system and the increased metabolic rate activity, due to a higher dependence on lactate fermentation as a preferential energy source, are common features between cancer cells and parasites. It is also well known that tumor cells use epigenetic processes to escape from therapy and immune surveillance [26]. Therefore the epigenome, including DNA methylation and histone modifications, have been thoroughly investigated to identify novel cancer targets in drug discovery programmes [27]. Due to the similarities between cancer cells and parasites, targeting the epigenome has emerged as a new strategy for the treatment of parasitic diseases including schistosomiasis [28-30].

HDACs are the most investigated epigenetic targets in humans and a variety of specific inhibitors, active on cancer cells, have already been discovered [31]. HDAC inhibitors have also been explored in the past years as putative candidate drugs to fight several human parasitic diseases including leishmaniasis, malaria, schistosomiasis, toxoplasmosis and trypanosomiasis [32-34]. Importantly, class I HDACs (SmHDAC1, 3 and 8) are expressed in all developmental stages of Schistosoma, and SmHDAC8 has been shown to be the most abundant [35]. Moreover, several studies indicate that targeting histone deacetylation activity could represent a promising therapeutic strategy [36-38].

In order to identify new anti-schistosomal molecules, we screened a small library of class I HDAC inhibitors against the larval stage of $S$. mansoni and selected four hits for further characterization on the adult stage of the parasite. Our study identified three novel compounds that impaired viability of both $S$. mansoni larval and adult stages. In addition, when used at sub-lethal doses two compounds, SmI-148 and SmI-558, drastically reduced the number of eggs laid by mature females in vitro and induced phenotype alterations in their reproductive system (ovary and oviduct). Finally, analysis of histone acetylation demonstrated the effect on enzymatic activity of two out of four compounds.

\section{Methods}

Reagents

Dimethyl sulphoxide (DMSO), percoll, Nonidet P-40 (NP40), fetal bovine serum (FBS), thimerosal, gambogic acid, trichostatin A (TSA), bovine serum albumin (BSA), carmine-red and Canada balsam were purchased from Sigma-Aldrich (Saint Lous, USA); CellTiter-Glo (CTG) reagent from Promega (Madison, USA); Dulbecco-Modified Eagle's Medium (DMEM) with or without phenol red, HEPES, L-glutamine from Lonza (Basel, Switzerland); antibiotic-antimycotic reagent $(100 \times)$ from Thermo Fisher Scientific (Waltham, USA); HDAC1 enzyme (BMLSE456), substrate (BML-KI104) and developer solution BML-KI105) from Enzo Life Sciences, Inc (Farmingdale, USA); Dacinostat (S1095) from Selleckchem (Munich, Germany); the primary monoclonal anti- $\alpha$-tubulin antibody (DM1A) from Sigma-Aldrich; the anti-acetylated-lysine (Ac-K2-100) from Cell Signaling Technology (Danvers, USA); goat anti-mouse and anti-rabbit IgG $(\mathrm{H}+\mathrm{L})$-horseradish peroxidase secondary antibodies from Bio-Rad Laboratories (Hercules, USA).

\section{Collection of HDAC inhibitors}

The compound collection used in the present work consisted of approximately 1500 IRBM proprietary 
compounds with a range of activity against human HDACs. The collection was synthesized in the past two decades as part of multiple drug discovery efforts [39, 40]. Compounds, to be transferred both to biochemical and cell-based assays, were prepared from $10 \mathrm{mM}$ DMSO stock solutions. Mother solutions were serially diluted and transferred to assay plates by an acoustic droplet ejection device (ATS-100, EDC Biosystems, Fremont, USA).

\section{Human HDAC1 activity assay}

The buffer used in the assay was TBS $+1 \mathrm{mM}$ $\mathrm{MgCl}_{2}+0.1 \%$ BSA. Human HDAC1 was diluted to 1 $\mathrm{nM}$ in assay buffer and $15 \mu \mathrm{l}$ of the diluted enzyme mix were transferred to each well of compound containing microplates (P.N. 4316, Thermo Fisher Scientific). After $10 \mathrm{~min}$ incubation at room temperature, $5 \mu \mathrm{l}$ of assay buffer-diluted substrate (BML-KI104) was added to each well to a final concentration of 80 $\mu \mathrm{M}$. The reaction was incubated for $1 \mathrm{~h}$ at room temperature. To develop the reaction signal, $15 \mu \mathrm{l}$ of a concentrated (600-fold) assay buffer-diluted developer solution (BML-KI105) was transferred to each well with the addition dacinostat $(3 \mu \mathrm{M}$ final concentration) (S1095) to stop the reaction. Dacinostat (3 $\mu \mathrm{M})$ was also used as $100 \%$ inhibition reference, while DMSO was used as $0 \%$ inhibition reference. After $10 \mathrm{~min}$ incubation at room temperature the reaction signal was read at $360 \mathrm{~nm}$ excitation, 460 $\mathrm{nm}$ emission on an EnVision spectrophotometer (PerkinElmer, Waltham, USA).

\section{HeLa class I HDAC inhibition assay}

The buffer used in the assay was TBS $+0.25 \mathrm{mM}$ $\mathrm{MgCl}_{2}+0.02 \%$ BSA. Human cervical cancer HeLa cells $\left(1 \times 10^{4} \mathrm{c} / \mathrm{w}\right)$ were plated in DMEM complete medium with $10 \%$ FBS and without phenol red in a 384-well plate and left to recover for $4 \mathrm{~h}$ at $37{ }^{\circ} \mathrm{C}$, $5 \% \mathrm{CO}_{2}$ in a humidified atmosphere. After recovery, compounds were transferred to assay plates as per the compound preparation method. Then, $5 \mu \mathrm{l}$ of assay buffer-diluted substrate (BML-KI104) were added to each well to a final concentration of $400 \mu \mathrm{M}$. The reaction was incubated for $4 \mathrm{~h}$ at $37{ }^{\circ} \mathrm{C}, 5 \% \mathrm{CO}_{2}$ in a humidified atmosphere. To develop the reaction signal, $15 \mu \mathrm{l}$ of concentrated assay buffer-diluted developer solution (27-fold) (BML-KI105) were transferred to each well with the addition of 3\% NP40 and dacinostat $(6 \mu \mathrm{M}$ final concentration) (S1095) to stop the reaction. Dacinostat $(6 \mu \mathrm{M})$ was also used as the $100 \%$ inhibition reference, while DMSO was used as the $0 \%$ inhibition reference. After 10 min incubation at room temperature the reaction signal was read at $360 \mathrm{~nm}$ excitation, $460 \mathrm{~nm}$ emission on an EnVision spectrophotometer (PerkinElmer).

\section{Maintenance of the S. mansoni life-cycle}

As previously described, a Puerto Rican strain of $S$. mansoni was maintained by passage through albino Biomphalaria glabrata, as the intermediate host, and ICR (CD-1) outbred female mice as the definitive host [41]. Female 4- to 7-week-old mice (Envigo, Udine, Italy) were housed with the following conditions: $22{ }^{\circ} \mathrm{C}$, $65 \%$ relative humidity, $12 / 12 \mathrm{~h}$ light/dark photocycle, standard food and water ad libitum. Mice were infected with 150-200 single sex or double sex S. mansoni cercariae by the tail immersion technique. Adult parasites were harvested from mice 7-8 weeks after infection by reversed perfusion of the hepatic portal system and mesenteric veins.

\section{Preparation of parasites, viability assays and egg counts}

Schistosomula were obtained by mechanical transformation of cercariae using an optimized version of the protocol of Brink et al. [42], previously described by Protasio et al. [43] and adapted in our laboratory [41].

The viability assay on schistosomula (100/well) was carried out as previously described in 384-well, black, tissue culture plates [41]. Briefly, compounds dissolved in DMSO were transferred to wells by using the acoustic droplet ejection technology (ATS-100, EDC Biosystems). DMSO (vehicle) and gambogic acid $(10 \mu \mathrm{M})$ were used as the negative and positive control in each plate, respectively. Schistosomula were incubated in DMEM medium (without phenol red) with the compounds for $24 \mathrm{~h}$ at $37{ }^{\circ} \mathrm{C}$ and $5 \% \mathrm{CO}_{2}$. Next, CellTiter-GLO reagent (CTG) $(30 \mu \mathrm{l})$ was added and a luminescence signal, proportional to the amount of ATP present in the well, was measured $30 \mathrm{~min}$ after CTG addition. The relative luminescence unit (RLU) was obtained by a charge-coupled device (CCD)-based detector (ViewLux, PerkinElmer). The data were analyzed using GraphPad Prism v6.0c software (San Diego, USA). The percentage of dead schistosomula for each compound was calculated as the ATP reduction against vehicle $(0 \%)$ and gambogic acid $(100 \%)$.

For studies on adult worms, 5-10 males or couples were incubated with selected compounds in 3-5 ml DMEM complete tissue culture medium for up to 7 days [44]. The compound was given to parasites in vitro only once without medium addition and/or replacement.

Survival was monitored daily under a Leica MZ12 stereomicroscope and scores assigned, as previously reported, based on phenotypes [41]. Specifically, we adopted the following phenotype scoring criteria: 3, plate-attached, good movements, clear; 2, slower or diminished movements, darkening, minor tegumental damage; 1, movements heavily lowered, darkening, tegument heavily damaged; 0 , dead, lack of any 
movement. For each sample the total score was determined with the following formula:

$$
\text { Total score }=\frac{\sum(\text { Worm scores })}{\text { Number of worms }}
$$

The percentage severity score (viability) was assigned in at least three independent experiments for each compound, relative to vehicle (DMSO). The number of eggs produced by all worm couples in vitro was manually counted at day 3 upon compound treatment using an inverted Leica DM IL microscope (Leica Microsystems, Wetzlar, Germany).

\section{Western blot analysis}

Five adult male worms were recovered $24 \mathrm{~h}$ after HDAC inhibitor-treatment and washed twice in cold PBS. Parasites were processed by using a modified version of the protocol of Dubois et al. [36]. Briefly, adult worms were resuspended in lysis buffer $(200 \mu \mathrm{l}$ of PBS containing 50 mM HEPES, $150 \mathrm{mM} \mathrm{NaCl}, 5 \mathrm{mM}$ EGTA, 1\% Triton $\mathrm{X}-100)$ and sonicated 6 times for $15 \mathrm{~s}$. Next, the samples were centrifuged for $10 \mathrm{~min}\left(14,000 \times g\right.$ at $\left.4{ }^{\circ} \mathrm{C}\right)$, the supernatants removed and the pellets (containing the enriched-nuclear proteins) resuspended in protein loading buffer $(100 \mu \mathrm{l})$. They were then sonicated 6 times for $15 \mathrm{~s}$, boiled, and analyzed by SDS-PAGE and western blot with anti- $\alpha$-tubulin DM1A (1:5000) or anti-acetylated-lysine (1:4000) following the antibody manufacturer's instructions. A Chemidoc XRS (Bio-Rad) with a chemi-luminescent camera and ImageLab 4.0 software were used for the acquisition of images. Each western blot analysis was calibrated by ponceau-staining.

\section{Carmine-red staining and confocal laser scanning microscopy analysis}

Carmine-red staining was performed as previously described [44]. Images were taken on an Olympus FV1200 confocal laser-scanning microscope using an UPlanFLN $40 \times$ immersion oil objective $(\mathrm{NA}=1.30)$ with optical pinhole at $1 \mathrm{AU}$ and a multiline argon laser at $488 \mathrm{~nm}$ as the excitation source. The images were collected as a single stack.

\section{Statistical analysis}

All statistical tests were performed using GraphPad Prism v.6.0c software. All viability data are shown as the mean \pm standard error of the mean $(\mathrm{SEM})$ or \pm standard deviation (SD) as indicated. Differences in the viability scores were analyzed by Student's t-test. For all experiments, $P$-values $<0.05$ were considered to be statistically significant.

\section{Results and discussion}

Identification of compounds able to kill schistosomula from a HDAC inhibitor collection

A compound collection comprising approximately 1500 molecules was screened at a single concentration of $10 \mu \mathrm{M}$ using a previously described schistosomula viability assay [41]. The quality of the screening was assessed by the Z' value [45], calculated for each tested plate using vehicle (DMSO) and gambogic acid dispensed wells as negative and positive controls, respectively. The Z' was above the 0.5 threshold in all plates, the lowest acceptable value for a robust assay (Fig. 1a). The percentage of dead schistosomula for each compound was calculated as the ATP reduction against vehicle $(0 \%)$ and gambogic acid $(100 \%)$. The positivity threshold was arbitrarily set to $50 \%$ (Fig. 1b). By using this threshold, 27 active compounds were identified $(1.6 \%$ hit rate). The active compounds were quality-controlled by LC-MS and re-tested in the schistosomula viability assay at three different concentrations $(50,10$ and $2 \mu \mathrm{M})$ for confirmation. The activity of 10 compounds was not confirmed and an additional 10 compounds consisted of < $90 \%$
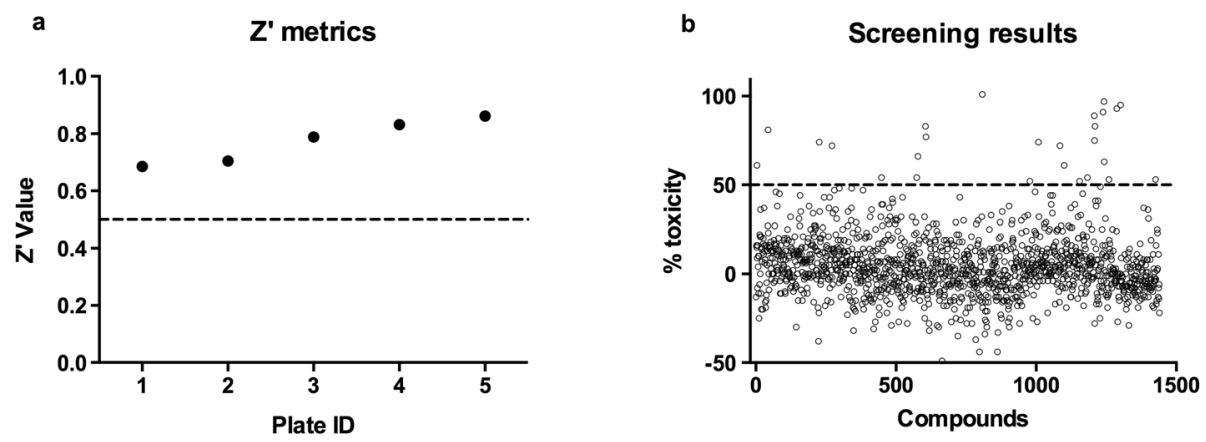

Fig. 1 HDAC inhibitors collection screening. a For each microplate the quality of the assay was carried out by the Z' calculation. Positive controls wells $(n=16)$ were treated with $10 \mu \mathrm{M}$ gambogic acid whereas negative wells $(n=16)$ were treated with vehicle (DMSO). All plates were found to be above the 0.5 quality threshold. $\mathbf{b}$ The percentage of ATP reduction (death of schistosomula) for all compounds (tested at $10 \mu \mathrm{M}$ ) normalized against DMSO and gambogic acid 
impurities. Four compounds of the remaining seven were identified as prototype molecules for further profiling.

Next, the selected compounds were tested in a dose-response fashion in the schistosomula viability assay: all had potencies in the range of $10-20 \mu \mathrm{M}$ (Fig. 2a). Furthermore, they were assayed for their activity on human recombinant HDAC1 and on a cell-based assay, which measures class I HDAC inhibition in human HeLa cells, and the results showed a different sensitivity to the compounds (Fig. 2b). In particular, for both assays SmI-124 exhibited very good activity whilst SmI-148 and SmI-646 showed modest or absent activity, respectively. In addition, SmI-558 was apparently not active against class I HDACs in cells. This finding suggests that there is the potential to gain specificity for $S$. mansoni HDACs with respect to human ones. The structural features of the compounds tested, shown in Fig. 2c, is the presence of different Zn-binding groups (ketone, carboxylate esters and secondary amide) in the terminal position of an alkyl chain linked to a five membered heterocycle having a biaryl substituent (naphthyl or quinolone).

\section{Compound-treatment affects $S$. mansoni adult parasite viability and egg production in vitro}

The efficacy of the hit compounds, selected in the schistosomula screening, was also assessed by survival assays and bright-field microscopy analyses on adult male worms. Parasites were subjected to treatment with the compounds (10 and $20 \mu \mathrm{M})$ and checked daily for any morphological or lethal alteration. As shown in Fig. 3, three out of four compounds (SmI-124, SmI-148 and SmI-558) led to a strong decrease in viability within seven days of compound exposure using both concentrations. These compounds were then tested against mature pairs using to monitor the effect on viability for both male and female worms as well as to detect any differences on egg laying (Fig. 4a). We found that all three compounds exhibited a lethal action when used at the highest concentration (10 $\mu \mathrm{M})$ but not at the lowest one $(5 \mu \mathrm{M})$. Moreover a strong reduction in the number of eggs laid by worm pairs treated with $5 \mu \mathrm{M}$ SmI-148 and SmI-558 three days after treatment was recorded (Fig. 4b). In addition, as SmI-558 led to a decreased viability of parasites (about 50\%) three days after the treatment with $5 \mu \mathrm{M}$, pairs were also assayed with lower

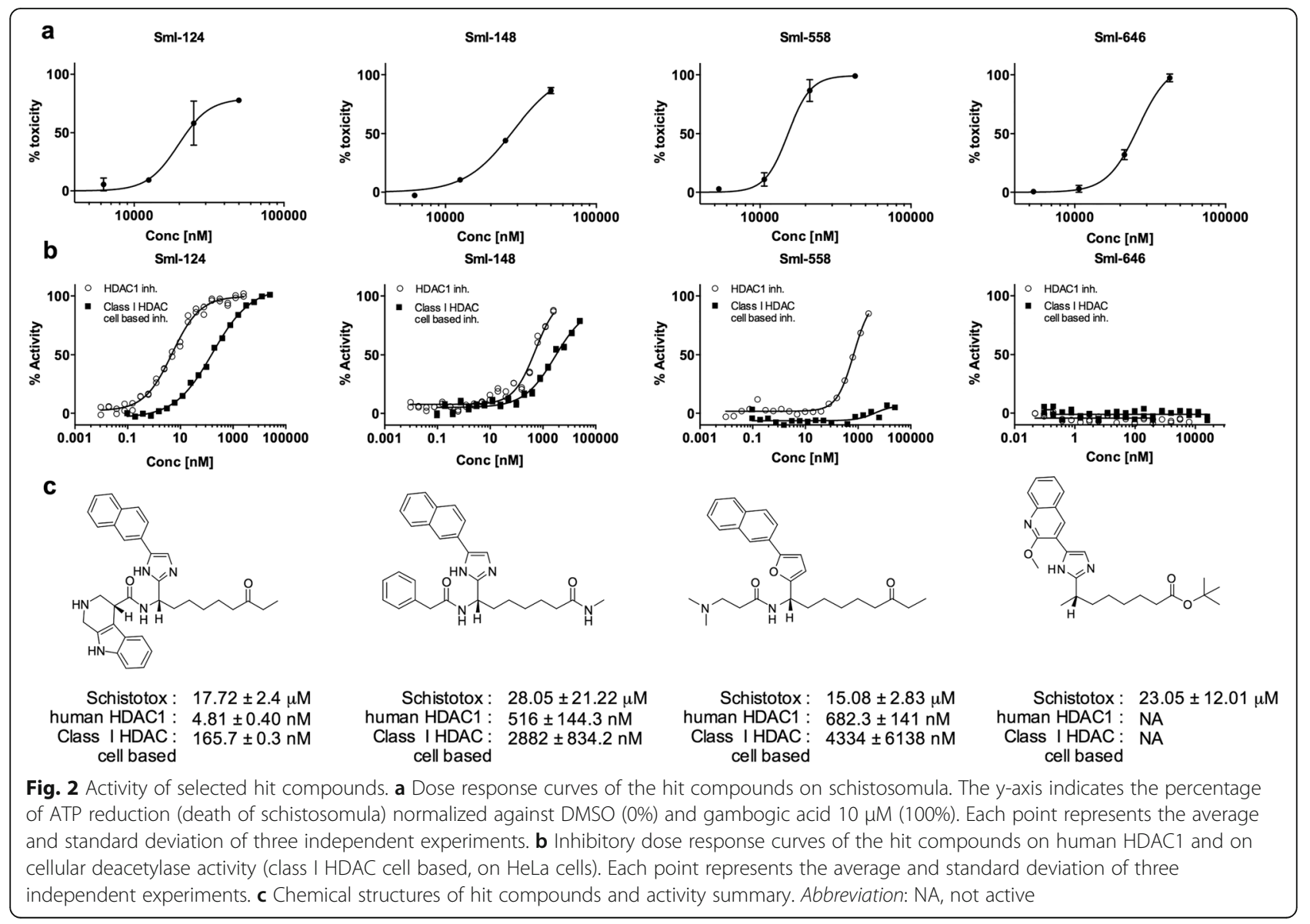



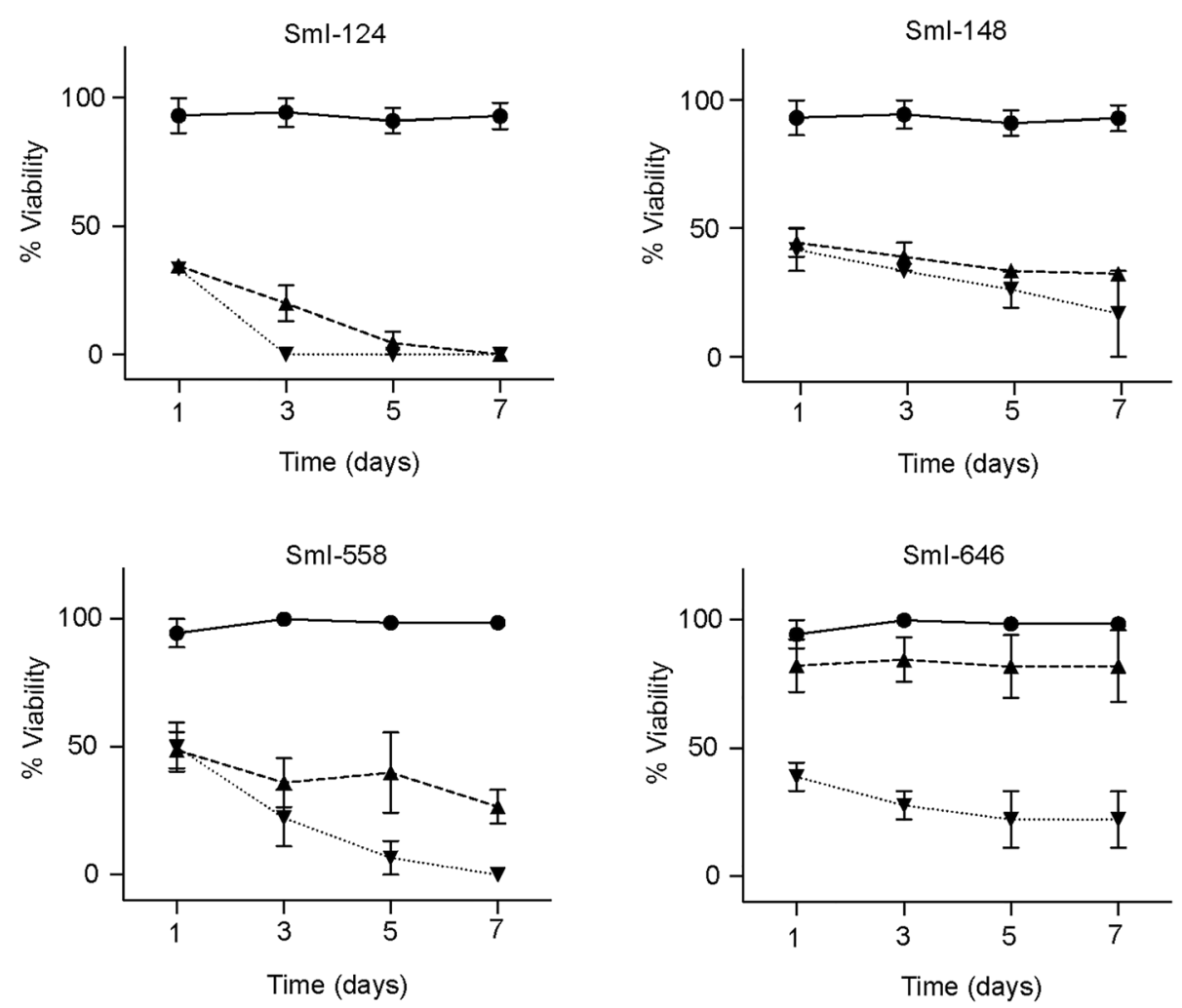

Fig. 3 Activity of selected hit compounds on adult S. mansoni worms. The percentage of viability of adult male worms, exposed to the indicated compounds at the concentration of $10 \mu \mathrm{M}$ (triangle) and $20 \mu \mathrm{M}$ (inverted triangle), scored at different time points (x-axis). DMSO (vehicle, circle) represents the negative control. Each point represents the average \pm SEM of three independent experiments
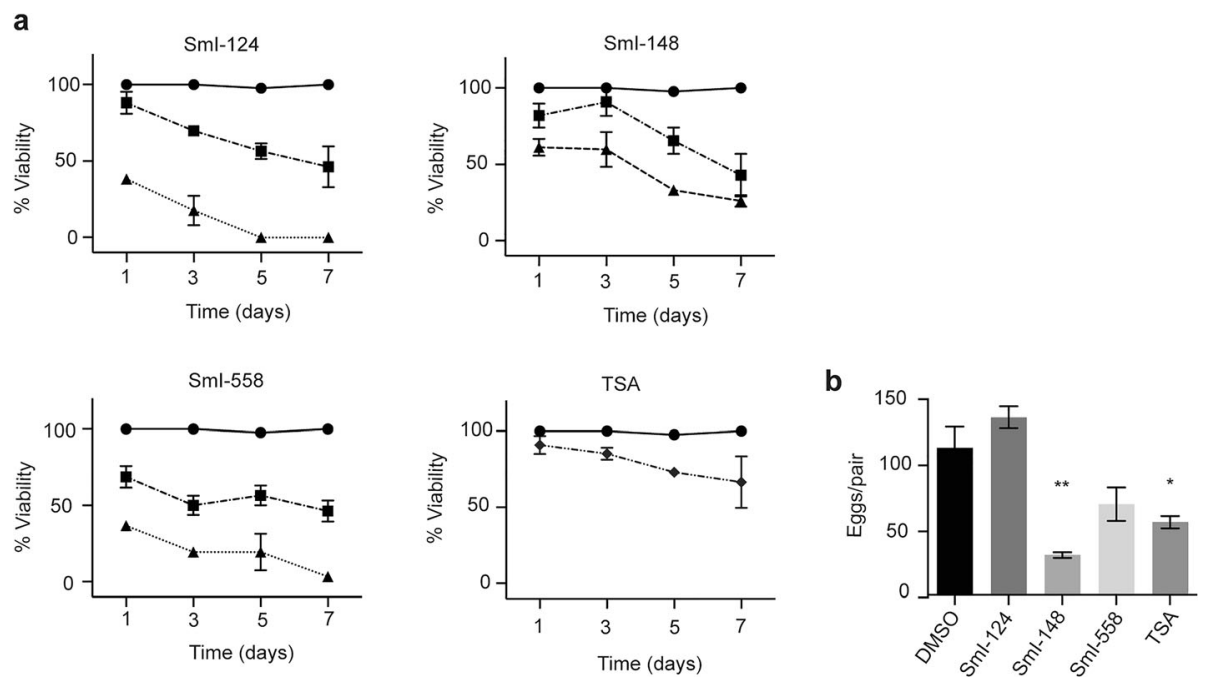

Fig. 4 Effects of selected hit compounds on S. mansoni adult worm pairs viability and egg production in vitro. a Viability curves of adult worm pairs treated with Sml-124, Sml-148, and Sml-558 at 5 (square) or $10 \mu \mathrm{M}$ (triangle) concentrations. DMSO (circle) and trichostatin A (TSA) (diamond) treatments represent the negative and positive controls, respectively. b Total egg counts laid by pairs treated with a sub-lethal dose (5 $\mu \mathrm{M})$ of the indicated compounds normalized to worm couples are shown. The mean data \pm SEM of three independent experiments are shown. The levels of statistical significance are indicated above bars; ${ }^{*} P<0.05,{ }^{* *} P<0.01$, Student's t-test 
concentrations of the compound. Therefore, using SmI-558 at $2.5 \mu \mathrm{M}$ concentration worms appeared fully viable but the number of eggs laid in vitro by female worms did not differ from that of control samples. The effects of SmI-148 and SmI-558 on both schistosomula and mature worms viability, along with their negative impact on egg laying, are of particular interest for the development of anti-schistosomal compounds.

The HDAC inhibitors Sml-124 and Sml-148 induce histone hyperacetylation in adult worms

In order to investigate the activity of the selected compounds on HDAC, the levels of histone acetylation were investigated 24 hours after exposure of parasites to the inhibitors $(10 \mu \mathrm{M})$ by immunoblot of nuclear-enriched cell fractions. Our results indicate that SmI-148- and SmI-124-treated worm lysates showed histone hyperacetylation comparable to the levels found in the pan-inhibitor TSA-treated worms with the strongest effect exerted by the first compound (Fig. 5). Three distinct bands ranging from $\sim 11$ to $\sim 16 \mathrm{kDa}$ were detected: the lower mobility bands likely correspond to hyperacetylated forms of $\mathrm{H} 2 \mathrm{~B}$ $(\sim 13 \mathrm{kDa})$ and H2A ( 16 kDa) [46] whereas the one migrating faster is ascribable to histone $\mathrm{H} 4(11 \mathrm{kDa})$. It is interesting to note that the strongest hyperacetylation signal was in histone $\mathrm{H} 2$ which along with $\mathrm{H} 3$ and $\mathrm{H} 4$ are considered the core histones.

HDACs target histones and also other nuclear and cytoplasmic proteins such as cytoskeletal proteins, chaperones, transcription factors, proteins involved in chromatin remodeling, and signaling mediators. They

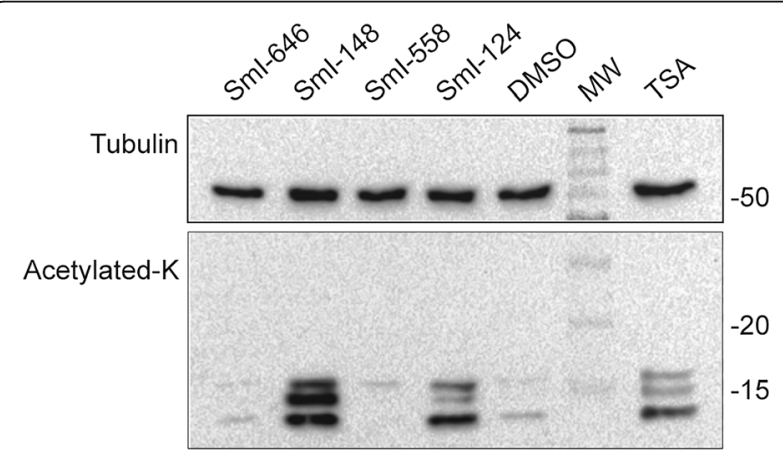

Fig. 5 Histone acetylation analysis in HDAC inhibitors-treated adult S. mansoni parasites. Representative immunoblots of the histone-enriched protein fractions extracted from S. mansoni adult worms incubated with anti-acetylated lysine antibody (acetylated-K) or anti-tubulin, as a sample loading control. Worms have been treated for $24 \mathrm{~h}$ with $1 \mu \mathrm{M}$ of the HDAC pan-inhibitor, TSA or with the indicated HDAC inhibitors $(10 \mu \mathrm{M})$ or with DMSO (vehicle) used as control. Lane MW: molecular weight marker size. The western blot is representative of 3

independent experiments are therefore also named lysine deacetylases [47]. Indeed, proteome-wide lysine acetylation in 42-days-old S. japonicum worms identified approximately 1000 acetylated proteins [48]. Furthermore, a comparative analysis of 18 - and 28-days-old S. japonicum worm acetylation profiles indicated that acetylation modulated several biological functions during parasite development, including gene transcription and translation, glycometabolism and lipid metabolism, muscular movement and protein degradation [49]. Therefore, we cannot exclude that SmI-558, as well as SmI-124 and SmI-148, target non-histone proteins. This aspect remains to be investigated.

\section{Sml-148 and Sml-558 treatments cause alterations of parasite reproductive systems}

The phenotypic alterations, induced by the selected HDAC inhibitors, were also investigated by carmine-red staining and confocal laser scanning microscopy analysis. Worm pairs treated with SmI-148 showed notable morphological alterations in both testes and ovaries. Specifically, a decrease of cellularity in testes lobes and marked morphological changes in the ovaries were observed (Fig. 6). In particular, the ovaries of SmI-148-treated samples appeared smaller with a decrease in the numbers of both immature and mature oocytes compared to controls (Fig. 6). In addition, the occurrence of eggs in the ootype and uterus was rare and eggs when present were not properly formed. The sub-lethal dose $(2.5 \mu \mathrm{M})$ of SmI-558, that did not impact egg production in vitro (Fig. 4), induced however morphological alterations in the female reproductive organs. The ovaries of SmI-558-treated parasites preserved their overall morphology, but displayed oocytes (both immature and mature) with a wide range of degeneration including black spots in the mature oocytes (Fig. 6). Moreover, the uterus showed dysplastic eggs and dispersed cells and the ootype presented disorganized oocytes and vitelline cells (Fig. 6). The female worms of pairs treated with SmI-148 or SmI-558 at $5 \mu \mathrm{M}$ also showed alterations in the vitellarium, a decreased cellularity in vitelline follicles and an increase in black-stained cavities (Fig. 6). In contrast, treatment of worm couples with SmI-124 did not cause major alterations in the male and female reproductive systems: gut dilation with detachment of the gastrodermis and accumulation of particle aggregates in the lumen was the main alteration observed. Gut dilatation was also observed in parasites treated with SmI-558 (Fig. 7).

Overall these results highlight an effect of HDAC inhibitors SmI-148 and SmI-558 on the female 


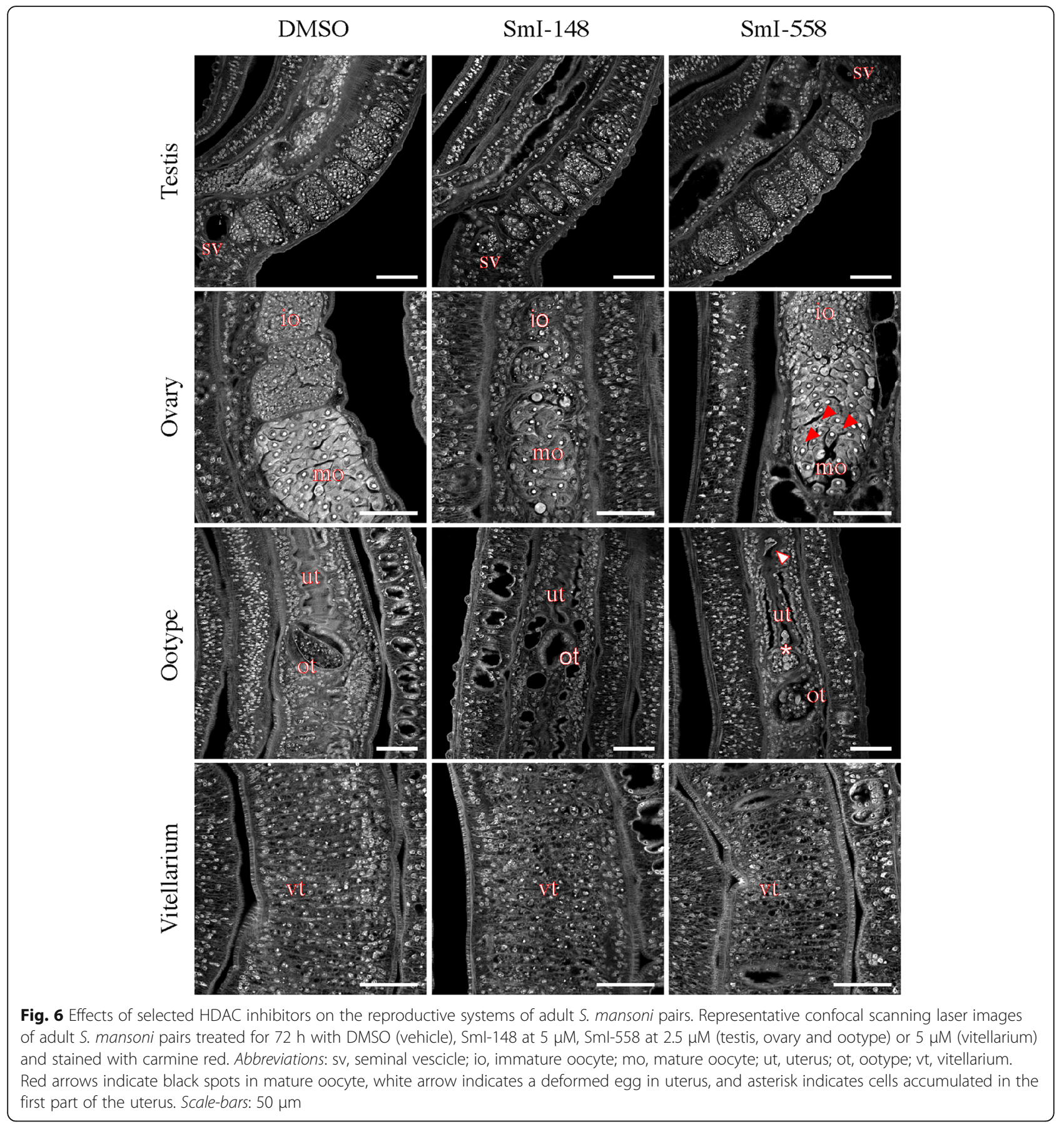

reproductive system that is consistent with their detrimental effect on egg production.

\section{Conclusions}

In summary, we successfully screened a library of HDAC inhibitors on S. mansoni larvae (schistosomula) and further characterized four selected hits on adult parasites. Three of them (SmI-124, SmI-148 and SmI-558) were active on both larval and adult stages with SmI-148 and SmI-558 impairing both egg production and causing morphological alterations of the parasite reproductive systems. Importantly, SmI-148 showed a modest activity on human recombinant HDAC1 and a class I HDACs assay in HeLa cells and SmI-558 was apparently not active against class I HDACs in cells. Further profiling of both compounds against selected human and S. mansoni 

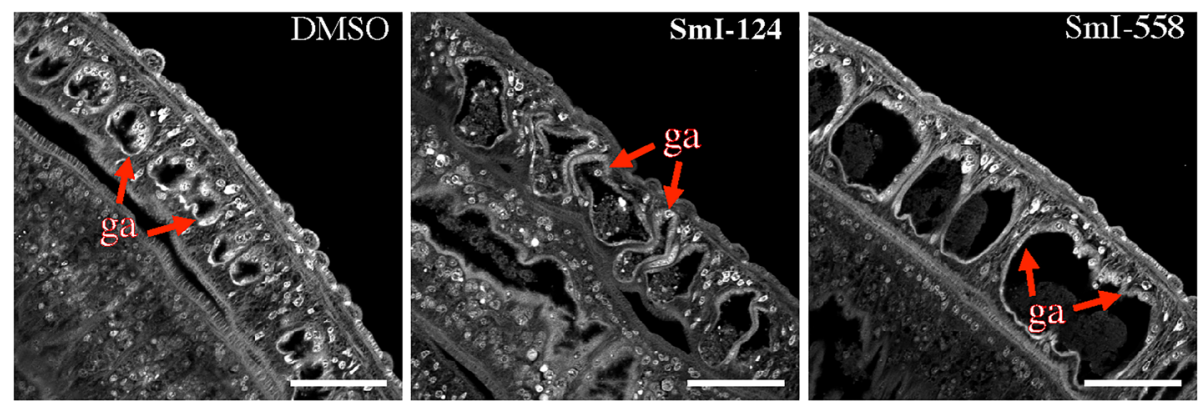

Fig. 7 Effects of selected HDAC inhibitors on adult S. mansoni gut. Representative confocal scanning laser images of adult S. mansoni males treated for $72 \mathrm{~h}$ with Sml-558 and Sml-124 (5 $\mu \mathrm{M})$ and stained with carmine red. In the figure gastrodermis (ga) is indicated. Scale-bars: $50 \mu \mathrm{m}$

HDACs, including SmHDAC8, could lead to the development of parasite-specific HDAC inhibitors to be further characterized also in murine models of schistosomiasis.

\section{Abbreviations}

HDAC: histone deacetylase; PZQ: praziquantel; TSA: trichostatin A:

DMSO: dimethyl sulphoxide; NP40: Nonidet P-40; FBS: fetal bovine serum;

BSA: bovine serum albumin; CTG: CellTiter-Glo; Sm: Schistosoma mansoni

\section{Acknowledgements}

We are grateful to members of the Institute Cell Biology and Neurobiology, National Research Council, Donato Cioli and Livia PicaMattoccia, for sharing with us their expertise and to Dario Presutti for his support in mouse breeding and colony management. Special thanks are due to Fabrizio Lattanzi and Stefania Colantoni for mouse husbandry.

\section{Funding}

This work was partially supported by the CNR (National Research Council)CNCCS (Collezione Nazionale di Composti Chimici e Centro di screening) "Rare, Neglected and Poverty Related Diseases - Schistodiscovery Project" (DSB.AD011.001.003) (GR and AB); by Regione Lazio/CNR/CNCCS -Development of scientific and technological platforms and innovative molecular libraries for rare and neglected diseases: Schistosoma and HDAC inhibitors screening (DCM.AD003.014.002) (GR and AB); and Ministero dell'Istruzione, dell'Università e della Ricerca PRIN 20154JRJPP_006 "Towards multi-stage drugs to fight poverty related and neglected parasitic diseases: Synthetic and natural compounds directed against Leishmania, Plasmodium and Schistosoma life stages and assessment of their mechanisms of action" (GR). The funders had no role in study design, data collection and analysis, decision to publish, or preparation of the manuscript.

\section{Availability of data and materials}

All data generated and/or analyzed during this study are included in this article.

\section{Authors' contributions}

$A G, G P a o, A B$ and $G R$ designed the experiments and analyzed the data. AG, $F S, N G, R G, E N, C L$ and GPap performed the experiments and analyzed the data. GR conceived the work, supervised the overall project and drafted the first version of the manuscript. $A G, F S, R G$ and $A B$ critically revised the manuscript. All authors read and approved the final manuscript.

\section{Authors' information}

$\mathrm{CL}$ contributed to this work during her PhD Programme in Genetics and Molecular Biology of Sapienza University of Roma at the National Research Council, Institute of Cell Biology and Neurobiology, Monterotondo (Roma), Italy. She is currently at the Biology Department, IRBM Science Park SpA, Pomezia, Italy.

\section{Ethics approval}

Animal work was approved by the National Research Council, Institute of Cell Biology and Neurobiology animal welfare committee (OPBA) and by the competent authorities of the Italian Ministry of Health, DGSAF, Rome (authorization no. 25/2014-PR). All experiments were conducted in respect to the $3 R$ rules according to the ethical and safety rules and guidelines for the use of animals in biomedical research provided by the relevant Italian law and European Union Directive (Italian Legislative Decree 26/2014 and 2010/ 63/EU) and the International Guiding Principles for Biomedical Research involving animals (Council for the International Organizations of Medical Sciences, Geneva, Switzerland).

\section{Consent for publication}

Not applicable.

\section{Competing interests}

The authors declare that they have no competing interests.

\section{Publisher's Note}

Springer Nature remains neutral with regard to jurisdictional claims in published maps and institutional affiliations.

\section{Author details}

'National Research Council, Institute of Cell Biology and Neurobiology, Campus A. Buzzati-Traverso, Monterotondo (Roma), Italy. ${ }^{2}$ Biology Department, IRBM Science Park SpA, Pomezia, Italy. ${ }^{3}$ Chemistry Department, IRBM Science Park SpA, Pomezia, Italy.

Received: 19 September 2018 Accepted: 12 December 2018 Published online: 27 December 2018

\section{References}

1. Colley DG, Bustinduy AL, Secor WE, King CH. Human schistosomiasis. Lancet. 2014;383:2253-64

2. Hotez PJ, Kamath A. Neglected tropical diseases in sub-saharan Africa: review of their prevalence, distribution, and disease burden. PLoS Negl Trop Dis. 2009:3:e412

3. Steinmann P, Keiser J, Bos R, Tanner M, Utzinger J. Schistosomiasis and water resources development: systematic review, meta-analysis, and estimates of people at risk. Lancet Infect Dis. 2006;6:411-25.

4. Gray DJ, Ross AG, Li YS, McManus DP. Diagnosis and management of schistosomiasis. BMJ. 2011;342:d2651.

5. Basch P. Schistosomes: Development, Reproduction and Host Relations. New York: Oxford University Press; 1991.

6. Popiel I, Basch PF. Reproductive development of female Schistosoma mansoni (Digenea: Schistosomatidae) following bisexual pairing of worms and worm segments. J Exp Zool. 1984;232:141-50.

7. Kunz W. Schistosome male-female interaction: induction of germ-cell differentiation. Trends Parasitol. 2001;17:227-31.

8. Loverde PT, Chen L. Schistosome female reproductive development. Parasitol Today. 1991;7:303-8.

9. Cioli D, Pica-Mattoccia L, Basso A, Guidi A. Schistosomiasis control: praziquantel forever? Mol Biochem Parasitol. 2014;195:23-9. 
10. Doenhoff MJ, Cioli D, Utzinger J. Praziquantel: mechanisms of action, resistance and new derivatives for schistosomiasis. Curr Opin Infect Dis. 2008;21:659-67.

11. Aragon AD, Imani RA, Blackburn VR, Cupit PM, Melman SD, Goronga T, et al. Towards an understanding of the mechanism of action of praziquantel. Mol Biochem Parasitol. 2009;164:57-65.

12. Pica-Mattoccia L, Cioli D. Sex- and stage-related sensitivity of Schistosoma mansoni to in vivo and in vitro praziquantel treatment. Int J Parasitol. 2004; 34:527-33

13. Sabah AA, Fletcher C, Webbe G, Doenhoff MJ. Schistosoma mansoni: chemotherapy of infections of different ages. Exp Parasitol. 1986;61:294-303.

14. Xiao SH, Catto BA, Webster LT Jr. Effects of praziquantel on different developmental stages of Schistosoma mansoni in vitro and in vivo. J Infect Dis. 1985;151:1130-7.

15. N'Goran EK, Utzinger J, N'Guessan AN, Muller I, Zamble K, Lohourignon KL, et al. Reinfection with Schistosoma haematobium following school-based chemotherapy with praziquantel in four highly endemic villages in Côte d'Ivoire. Trop Med Int Health. 2001;6:817-25.

16. Dabo A, Doucoure B, Koita O, Diallo M, Kouriba B, Klinkert MQ, et al. Reinfection with Schistosoma haematobium and mansoni despite repeated praziquantel office treatment in Niger, Mali. Med Trop (Mars). 2000;60:351-5. (In French).

17. Cioli D, Botros SS, Wheatcroft-Francklow K, Mbaye A, Southgate V, Tchuente $L A$, et al. Determination of ED50 values for praziquantel in praziquantelresistant and -susceptible Schistosoma mansoni isolates. Int J Parasitol. 2004; 34:979-87.

18. Gryseels B, Mbaye A, De Vlas SJ, Stelma FF, Guisse F, Van Lieshout L, et al. Are poor responses to praziquantel for the treatment of Schistosoma mansoni infections in Senegal due to resistance? An overview of the evidence. Trop Med Int Health. 2001;6:864-73.

19. Melman SD, Steinauer ML, Cunningham C, Kubatko LS, Mwangi IN, Wynn $N B$, et al. Reduced susceptibility to praziquantel among naturally occurring Kenyan isolates of Schistosoma mansoni. PLoS Negl Trop Dis. 2009;3:e504.

20. Mwangi IN, Sanchez MC, Mkoji GM, Agola LE, Runo SM, Cupit PM, et al. Praziquantel sensitivity of Kenyan Schistosoma mansoni isolates and the generation of a laboratory strain with reduced susceptibility to the drug. Int J Parasitol Drugs Drug Resist. 2014;4:296-300.

21. Couto FF, Coelho PM, Araujo N, Kusel JR, Katz N, Jannotti-Passos LK, et al. Schistosoma mansoni: a method for inducing resistance to praziquantel using infected Biomphalaria glabrata snails. Mem Inst Oswaldo Cruz. 2011; 106:153-7.

22. Fallon PG, Doenhoff MJ. Drug-resistant schistosomiasis: resistance to praziquantel and oxamniquine induced in Schistosoma mansoni in mice is drug specific. Am J Trop Med Hyg. 1994;51:83-8.

23. Ismail MM, Taha SA, Farghaly AM, el-Azony AS. Laboratory induced resistance to praziquantel in experimental schistosomiasis. J Egypt Soc Parasitol. 1994;24:685-95.

24. Sabra AN, Botros SS. Response of Schistosoma mansoni isolates having different drug sensitivity to praziquantel over several life cycle passages with and without therapeutic pressure. J Parasitol. 2008:94:537-41.

25. Ashall F. Cancer cells and parasites: two of a kind. Trends Biochem Sci. 1986: 11:518-20.

26. Jones PA, Issa JP, Baylin S. Targeting the cancer epigenome for therapy. Nat Rev Genet. 2016;17:630-41.

27. Brien GL, Valerio DG, Armstrong SA. Exploiting the epigenome to control cancer-promoting gene-expression programs. Cancer Cell. 2016;29:464-76.

28. Hailu GS, Robaa D, Forgione M, Sippl W, Rotili D, Mai A. Lysine deacetylase inhibitors in parasites: past, present, and future perspectives. J Med Chem. 2017;60:4780-804

29. Jeffers V, Yang C, Huang S, Sullivan WJ Jr. Bromodomains in protozoan parasites: evolution, function, and opportunities for drug development. Microbiol Mol Biol Rev. 2017:81:e00047-16

30. Pierce RJ, Dubois-Abdesselem F, Lancelot J, Andrade L, Oliveira G. Targeting schistosome histone modifying enzymes for drug development. Curr Pharm Des. 2012;18:3567-78.

31. Arrowsmith $\mathrm{CH}$, Bountra C, Fish PV, Lee K, Schapira M. Epigenetic protein families: a new frontier for drug discovery. Nat Rev Drug Discov. 2012;11: 384-400.

32. Marek M, Oliveira G, Pierce RJ, Jung M, Sippl W, Romier C. Drugging the schistosome zinc-dependent HDACs: current progress and future perspectives. Future Med Chem. 2015;7:783-800.
33. Scholte LLS, Mourao MM, Pais FS, Melesina J, Robaa D, Volpini AC, et al. Evolutionary relationships among protein lysine deacetylases of parasites causing neglected diseases. Infect Genet Evol. 2017;53:175-88.

34. Chua MJ, Arnold MS, Xu W, Lancelot J, Lamotte S, Spath GF, et al. Effect of clinically approved HDAC inhibitors on Plasmodium, Leishmania and Schistosoma parasite growth. Int J Parasitol Drugs Drug Resist. 2017;7:42-50.

35. Oger F, Dubois F, Caby S, Noel C, Cornette J, Bertin B, et al. The class I histone deacetylases of the platyhelminth parasite Schistosoma mansoni. Biochem Biophys Res Commun. 2008;377:1079-84.

36. Dubois F, Caby S, Oger F, Cosseau C, Capron M, Grunau C, et al. Histone deacetylase inhibitors induce apoptosis, histone hyperacetylation and upregulation of gene transcription in Schistosoma mansoni. Mol Biochem Parasitol. 2009;168:7-15.

37. Lancelot J, Caby S, Dubois-Abdesselem F, Vanderstraete M, Trolet J, Oliveira $\mathrm{G}$, et al. Schistosoma mansoni sirtuins: characterization and potential as chemotherapeutic targets. PLoS Negl Trop Dis. 2013;7:e2428.

38. Marek M, Kannan S, Hauser AT, Moraes Mourao M, Caby S, Cura V, et al. Structural basis for the inhibition of histone deacetylase 8 (HDAC8), a key epigenetic player in the blood fluke Schistosoma mansoni. PLoS Pathog. 2013;9:e1003645.

39. Kinzel O, Llauger-Bufi L, Pescatore G, Rowley M, Schultz-Fademrecht C, Monteagudo $\mathrm{E}$, et al. Discovery of a potent class I selective ketone histone deacetylase inhibitor with antitumor activity in vivo and optimized pharmacokinetic properties. J Med Chem. 2009;52:3453-6.

40. Ontoria JM, Paonessa G, Ponzi S, Ferrigno F, Nizi E, Biancofiore I, et al. Discovery of a selective series of inhibitors of Plasmodium falciparum HDACs. ACS Med Chem Lett. 2016;7:454-9.

41. Lalli C, Guidi A, Gennari N, Altamura S, Bresciani A, Ruberti G. Development and validation of a luminescence-based, medium-throughput assay for drug screening in Schistosoma mansoni. PLoS Negl Trop Dis. 2015:9:e0003484.

42. Brink LH, McLaren DJ, Smithers SR. Schistosoma mansoni: a comparative study of artificially transformed schistosomula and schistosomula recovered after cercarial penetration of isolated skin. Parasitology. 1977;74:73-86.

43. Protasio AV, Dunne DW, Berriman M. Comparative study of transcriptome profiles of mechanical- and skin-transformed Schistosoma mansoni schistosomula. PLoS Negl Trop Dis. 2013;7:e2091.

44. Guidi A, Lalli C, Perlas E, Bolasco G, Nibbio M, Monteagudo E, et al. Discovery and Characterization of novel anti-schistosomal properties of the anti-anginal drug, perhexiline and its impact on Schistosoma mansoni male and female reproductive systems. PLoS Negl Trop Dis. 2016;10:e0004928.

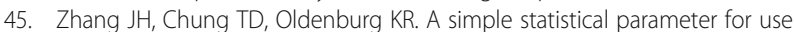
in evaluation and validation of high throughput screening assays. J Biomol Screen. 1999;4:67-73.

46. Miao F, Li S, Chavez V, Lanting L, Natarajan R. Coactivator-associated arginine methyltransferase-1 enhances nuclear factor-kappaB-mediated gene transcription through methylation of histone $\mathrm{H3}$ at arginine 17. Mol Endocrinol. 2006;20:1562-73.

47. Wang $Q$, Rosa BA, Nare B, Powell $K$, Valente $S$, Rotili $D$, et al. Targeting lysine deacetylases (KDACs) in parasites. PLoS Negl Trop Dis. 2015;9:e0004026.

48. Hong Y, Cao X, Han Q, Yuan C, Zhang M, Han Y, et al. Proteome-wide analysis of lysine acetylation in adult Schistosoma japonicum worm. J Proteomics. 2016;148:202-12.

49. Li Q, Zhao N, Liu M, Shen H, Huang L, Mo X, et al. Comparative analysis of proteome-wide lysine acetylation in juvenile and adult Schistosoma japonicum. Front Microbiol. 2017;8:2248.

\section{Ready to submit your research? Choose BMC and benefit from:}

- fast, convenient online submission

- thorough peer review by experienced researchers in your field

- rapid publication on acceptance

- support for research data, including large and complex data types

- gold Open Access which fosters wider collaboration and increased citations

- maximum visibility for your research: over $100 \mathrm{M}$ website views per year

At $\mathrm{BMC}$, research is always in progress.

Learn more biomedcentral.com/submissions 